Acta Protozool. (2017) 56: 317-322

www.ejournals.eu/Acta-Protozoologica

doi:10.4467/16890027AP.17.027.7829

\title{
PROTOZOOLOGICA
}

\section{Isolation of Thermotolerant Pathogenic Naegleria australiensis from Diverse Water Resources Including Household Drinking Water in Pakistan}

\author{
Tania TANVEER ${ }^{1,3}$, Abdul HAMEED ${ }^{2}$, Abdul-Aziz A. BIN-DUKHYIL ${ }^{1}$, Mohammed \\ ALAIDAROUS ${ }^{1}$, Abdul MATIN ${ }^{1,3}$ \\ ${ }^{1}$ Department of Medical Laboratory Sciences, College of Applied Medical Sciences, Majmaah University, Saudia Arabia; ${ }^{2}$ Institute \\ of Biomedical and Genetic Engineering, Islamabad, Pakistan; ${ }^{3}$ Department of Medical Lab Technology, University of Haripur, \\ Pakistan
}

$\begin{array}{ll}\text { Abbreviations } \\ \text { DNA } & \text { Deoxyribonucleic acid } \\ \text { dNTP } & \text { Deoxyribonucleotide triphosphate } \\ \text { E. coli } & \text { Escherichia coli } \\ \text { FLA } & \text { Free-living amoebae } \\ \text { ITS } & \text { Internal transcribed spacers } \\ \mathrm{KCl} & \text { Magnesium chloride } \\ \mathrm{LB} & \text { Luria-Bertini } \\ \mathrm{MgCl}_{2} & \text { Magnesium chloride } \\ \mathrm{NNA} & \text { Non-nutrient agar } \\ \text { PAM } & \text { Primary amoebic meningoencephalitis } \\ \text { PCR } & \text { Polymerase chain reaction }\end{array}$

Abstract. Naegleria is well recognized for primary amoebic meningoencephalitis which always results into death. To date there is not a single report demonstrating molecular identification of Naegleria from water resources of Pakistan thus the aim of the proposed study. Here, in total 135 various water samples (like domestic tap water, municipal water, sea water, well water, tube well water, canal water, boring water, sewage water, lake water and stream water) were collected across Pakistan and evaluated for Naegleria species. Naegleria australiensis (pathogenic) and Naegleria lovaniensis (non pathogenic) were isolated on non nutrient agar plates and were further identified by PCR and sequencing. To best of our knowledge we have described for the first time the isolation and molecular identification of thermotolerant pathogenic and non pathogenic Naegleria species from diverse water samples including drinking water across Pakistan. The presence of pathogenic Naegleria species in diverse water samples may add the health threat to the community.

Key words: Thermotolerant pathogenic Naegleria, Primary Amoebic Meningoencephalitis, Isolation, Molecular identification, Pakistan

Address for correspondence: Abdul Matin, Department of Medical Laboratory Sciences, College of Applied Medical Sciences, Majmaah University, Majmaah, 11952, Saudia Arabia; Tel.: +966-538569781; E-mail: amawan@live.co.uk, a.shafiqurhman@mu.edu.sa 


\section{INTRODUCTION}

Free-living amoebae (FLA) are highly diverse and show a worldwide distribution in various environments (Jamerson et al. 2009; Behets et al. 2007; Marciano-Cabral and Cabral 2007; Gianinazzi et al. 2009). Among FLA, Naegleria fowleri is well known to be the cause of primary amoebic meningoencephalitis in humans. More than 30 species of Naegleria have been reported from diverse environment and Naegleria fowleri for many years was the only species of this genus known to infect human. However, Naegleria australiensis is another pathogenic species of Naegleria which were identified as cause of PAM infections in Australia in 1965. Naegleria species have been isolated from natural and man-made aquatic habitats and even from normal drinking water (Schuster and Visvesvara 2004). It is generally acquired while swimming, diving in freshwater lakes and ponds (Martinez and Visvesvara 1997). The current study was planned after thirteen cases of Naegleria fowleri PAM in human were reported in a period of just 17 months in Karachi, Pakistan (Shakoor et al. 2011). We therefore undertook the following comprehensive survey to investigate the molecular identification of Naegleria in various water resources across Pakistan in order to evaluate the future possible risk for human health in the country.

\section{MATERIALS AND METHODS}

\section{Collection, processing \& cultivation of water sam- ples on non nutrient agar plates}

The water samples were collected across Pakistan from January 2012 to December 2012. In total 135 water samples (500 $\mathrm{ml}$ in volume each) from diverse sources like domestic tap water, , sea water, well water, tube well water, canal water, boring water, sewage water, lake water and stream water) were collected across Pakistan. Samples were collected and stored in sterilized polypropylene bottles labelled with date, time and place of collection. For Naegleria isolation plating assay was performed by modifying previous proto- cols (Ithoi et al. 2011). Briefly bacteria were grown in LB for overnight and were heat-killed as described previously (Matin and Jeong 2011). Heat-killed bacteria were poured on to non-nutrient agar plates and left for 2-3 minutes. The excess cultures were poured off and plates left to dry. Water samples $(500 \mathrm{ml})$ were filtrated through a nitrocellulose membrane (pore size: $0.2 \mu \mathrm{m}$ ) and filters were inserted upside down on non-nutrient agar plates seeded with E. coli and plates were incubated at 30,42 and $45^{\circ} \mathrm{C}$ (Fig. 1a). Plates were kept sealed in plastic bags to prevent drying and examined with an inverted microscope. Following, the detection of amoebas feeding on $E$. coli on agar, portions of the agar that contained these amoebas were excised and transferred onto newly bacteria-coated plates. After the amoebas of interest had migrated away from fungal and other contaminants, they were then transferred in agar cores to fresh, bacteria-coated agar plates. The agar plates were monitored for out-growth of Naegleria (trophozoites or cysts) microscopically for up to 2 weeks (Fig. 1b).

\section{DNA extraction from amoebic plaque obtained from non nutrient agar plates}

Amoeboid plaques were scraped off from the agar plates and DNA extraction was performed as described previously (Edagawa et al. 2009). Briefly, the cells were palleted at 10,000g for $5 \mathrm{~min}$ at RT followed by re-suspension in lysis buffer [ $(100 \mathrm{mM} \mathrm{KCl}$, $40 \mathrm{mM}$ Tris, $5 \mathrm{mM} \mathrm{MgCl}, 1 \%$ (w/v) Tween-20 and $100 \mu \mathrm{g} / \mathrm{ml}$ proteinase K)]. Next, tubes were incubated for $1 \mathrm{~h}$ at $56^{\circ} \mathrm{C}$ followed by $10 \mathrm{~min}$ incubation at $100^{\circ} \mathrm{C}$ to inactivate proteinase $\mathrm{K}$. Finally, the tubes were centrifuged at $10,000 \mathrm{~g}$ for $5 \mathrm{~min}$ and supernatants were collected and used as DNA template.

\section{Polymerase chain reaction analysis and sequencing}

Polymerase chain reaction (PCR) was performed using ribosomal internal transcribed spacers (ITS) primers by modifying previous protocols (Sheehan et al. 2003). Briefly, $25 \mu$ l of PCR mixture contained $2 \mu \mathrm{l}$ of the extracted DNA, $2.5 \mu \mathrm{l}$ of $10 \times$ PCR buffer (100 mM KCL, $20 \mathrm{mM} \mathrm{MgCl}, 20 \mathrm{mM}$ Tris- $\mathrm{HCl}[\mathrm{pH} 8.0]), 1.5 \mu l$ of $25 \mathrm{mM} \mathrm{MgCl}, 2 \mu \mathrm{l}$ of $2.5 \mathrm{mM}$ dNTP mixture, $0.75 \mu \mathrm{l}$ of each $100 \mu \mathrm{M}$ primer, and $0.25 \mu \mathrm{l}$ of $5 \mathrm{U} / \mu \mathrm{l}$ Ex Taq DNA polymerase. PCR-amplification was performed with a genus specific primer set ITS1_F and ITS1_R. Reaction conditions were $95^{\circ} \mathrm{C}$ for $5 \mathrm{~min}$ followed by 30 cycles of $95^{\circ} \mathrm{C}$ for $15 \mathrm{~s}, 53^{\circ} \mathrm{C}$ for $1 \mathrm{~min} 30 \mathrm{~s}, 72^{\circ} \mathrm{C}$ for $1 \mathrm{~min} 30 \mathrm{~s}$, and extension at $72^{\circ} \mathrm{C}$ for $10 \mathrm{~min}$. PCR products were electrophoresed on a $2 \%$ agarose gel and stained with a solution of $0.5 \mu \mathrm{g} / \mathrm{ml}$ of ethidium bromide and visualized under UV light. PCR products were purified using the Qiaquick PCR Purification Kit (Qiagen, Hilden, Germany) and sequenced using a sequencing kit (Applied Biosystems, Foster City, USA). A homology search was performed with BLAST software from the NCBI.

\footnotetext{
Fig. 1. (a) Water sample $(500 \mathrm{ml})$ was thoroughly mixed and filtrated through a cellulose nitrate filter and inoculated on non-nutrient agar (NNA) plate lawn with E. coli as described in Materials and Methods. (b) Amoebic plaque cysts $(\times 400)$ were morphologically observed up to 14 days on NNA plates under inverted microscope and images were taken. (c) Neighbour joining phylogenetic relationship between the partial sequences of 18S rRNA of Naegleria from isolates obtained in this study and reference sequences present in Gen Bank. The tree was generated in CLC Main Workbench version 6.6.2 using 1000 bootstrap replications. Branch length is proportional to the calculated genetic distance (scale shown).
} 

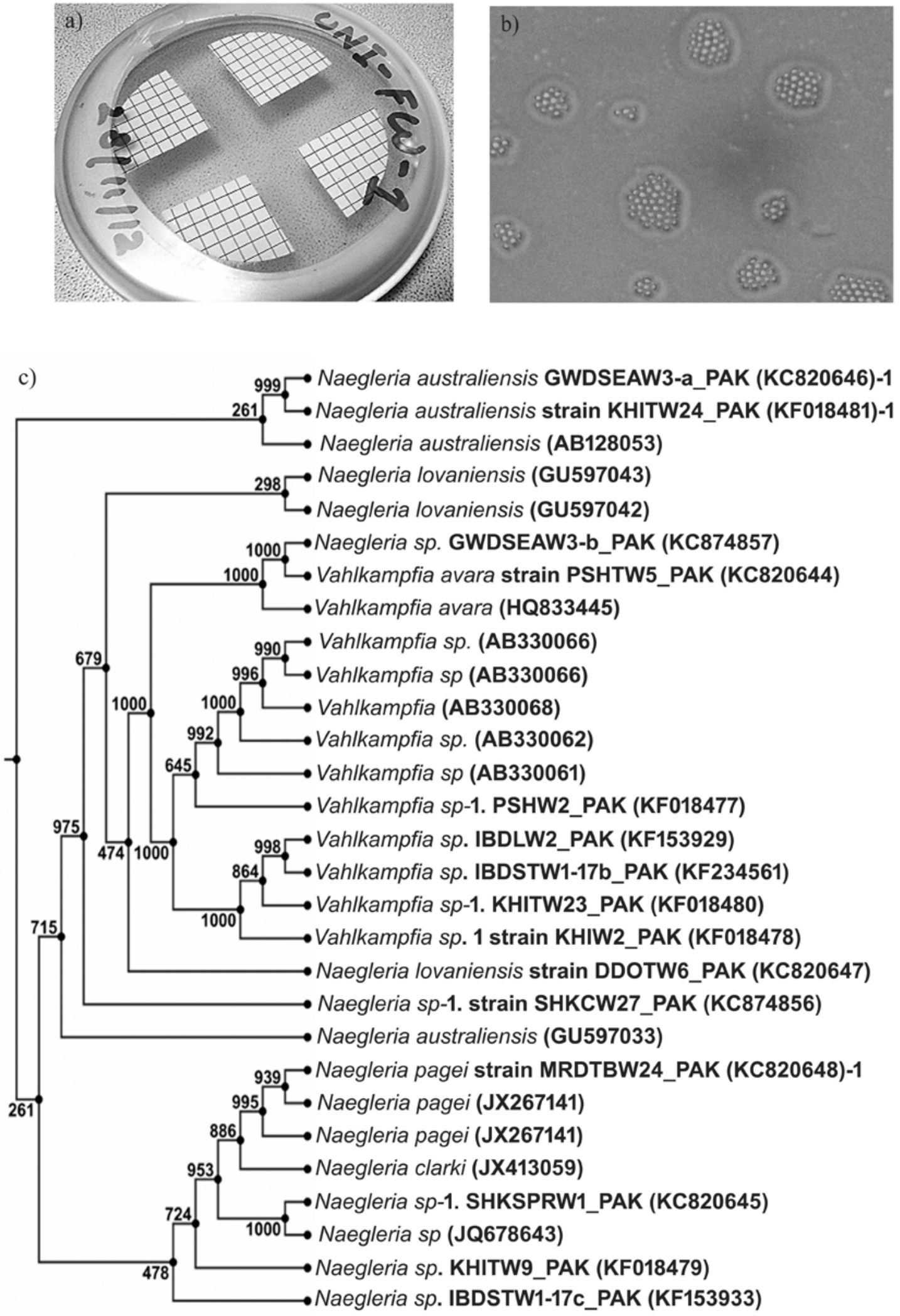


\section{Phylogenetic analysis}

Multiple alignment was performed using Clustal Omega (Larkin et al. 2007) in comparison with sequences available in GenBank for Naegleria. Phylogenetic reconstruction produced a gene tree by using neighbor-joining in the phylogenetic computer program (CLC main work bench 6.6.2) as described previously (Tamura et al. 2011).

\section{Accession numbers}

Sequences were deposited in Gen Bank with accession numbers KC820644-KC820648, KC874856, KC874857, KF018477KF018481, KF153929, KF153933 and KF234561.

\section{RESULTS AND DISCUSSION}

Overall, 96 out of $135(71.11 \%)$ water samples were positive for amoebae outgrowth on non nutrient agar plates at $30^{\circ} \mathrm{C}$ while $2(2.22 \%)$ at $42^{\circ} \mathrm{C}$ and $2(2.22 \%)$ at $45^{\circ} \mathrm{C}$. Cultures containing amoeba like outgrowth were further confirmed as Naegleria sp. after PCR and sequencing. Results revealed that 34 (35.41\%) samples were positive for Naegleria DNA which were further identified Naegleria sp. 09 (26.47\%) and Vahlkampfia sp. 06 (17.64\%) (Table 1). We successfully recovered Naegleria species on NNA plates at 30,42 and $45^{\circ} \mathrm{C}$. Interestingly, two Naegleria species were identified from a single water sample (GWD-SEAW3). It is noteworthy that in some of samples, Acanthamoeba was also isolated along with Naegleria species from the same water sample (data not shown). In support our group has recently isolated Acanthamoeba species from water resources of Khyber Pakhtunkhwa, Pakistan (Tanveer et al. 2015; Tanveer et al. 2013). In this regard further studies are necessary to evaluate the properties and quality of water which support amoebae species and Naegleria in particular. To the best of our knowledge, this is the first report demonstrating the exploration of various water resources and isolation and identification of pathogenic Naegleria species across Pakistan.

It is noteworthy findings of the present study that two thermotolerant species i.e. Naegleria australiensis and Naegleria lovaniensis were successfully recovered and identified. Like Naegleria fowleri, these identified Naegleria species tolerate temperatures up to $45^{\circ} \mathrm{C}$ and propagate tremendously during summer in natural water resources like lakes, rivers, geo-thermally heated water and industrial cooling water. These thermotolerant species are competitors that develop better than Naegleria fowleri at these temperatures. Furthermore it is well established that FLA also act as a host for sev- eral bacteria, and its ability to host bacterial pathogens has gained particular attention in recent years. These bacterial pathogens not only survive intracellularly but also multiply within them. This allows bacteria to transmit throughout the environment, evade host defences and/or chemotherapeutic drugs, and reproduce in sufficient numbers to produce disease. Upon favorable conditions, the increasing bacterial densities lyse their host amoebae and infect new amoebae and/or produce disease. This ability of FLA to resist harsh conditions (such as osmolarity, $\mathrm{pH}$ and extreme temperatures), especially during their cyst stage, suggest their usefulness as bacterial vectors. In particular, FLA cysts are notoriously resistant to chlorine. This poses clear challenges in eradicating bacterial pathogens from public water supplies, especially in developing countries (Rowbotham 1986; Michel et al. 2000). Furthermore, amoeba-bacteria interactions also effect bacterial virulence; i.e. pneumophila grown within amoeba exhibited increased motility, drug resistance and virulence compared with axenically grown Legionella (Greub and Raoult 2004). Prevalence of pathogenic bacteria inside drinking water reservoirs and their symbiotic relationship with Naegleria could be a potential question to be addressed in future.

According to the reports worldwide single specie Naegleria fowleri is responsible for PAM but none of the isolate could be identified as Naegleria fowleri during this study. However, the widespread presence of thermotolerant Naegleria in water supplies, especially Naegleria lovanensis, which is an indicator species for Naegleria fowleri, suggests this pathogenic amoeba may pose a risk to public health in the area (Marciano-Cabral and Cabral 2007). In support at least 13 PAM cases have already been reported in Karachi, Pakistan, who had no history of aquatic activities and it was believed the infections likely occurred through ablution with tap water (Shakoor et al. 2011). There are few reports of PAM caused by Naegleria have been reported from Pakistan previously (Saleem et al. 2009; Shariq et al. 2014). Seven out of 15 (46.66\%) Naegleria species have been identified during this study but originally 15 out of $59(25.42 \%)$ samples were positive for Naegleria DNA during PCR. Overall, the majority of water samples were amplified with Naegleria genus-specific primers, but conclusive sequences could not be obtained and still need to be further investigated. It is speculated that the amplified samples might be the novel species, which will be addressed in future studies. Therefore, the information presented in this report 
Naegleria species in water resources of Pakistan 321

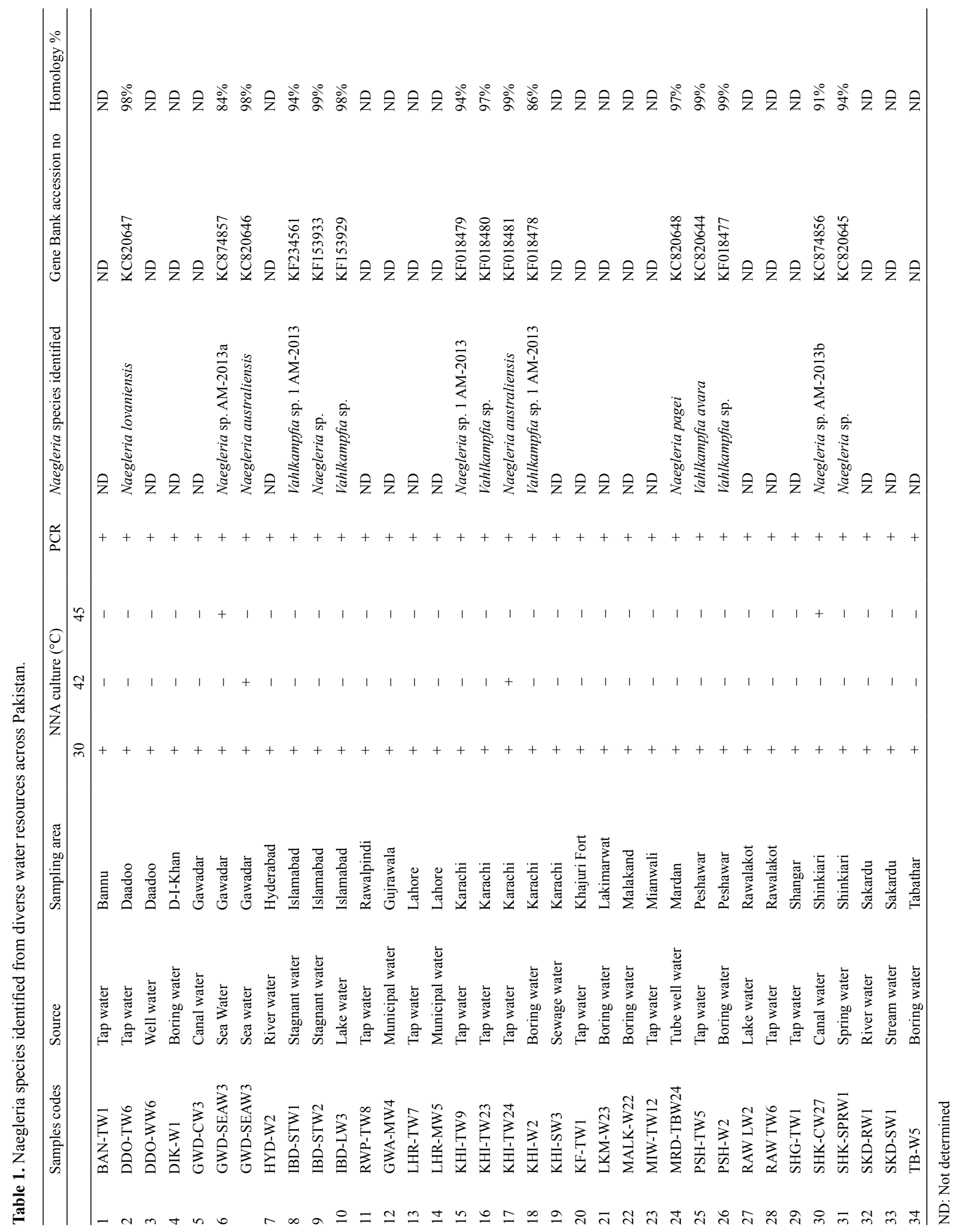


may serve as a base-line for further studies on the role of FLA in our environment especially in outbreaks of water borne diseases in Pakistan.

\section{CONCLUSIONS}

In conclusion, this study revealed for the first time isolation of thermotolerant both pathogenic and non pathogenic Naegleria species from various water samples including the drinking water in Pakistan. It should be stressed that the existence of pathogenic N. australiensis in diverse water sources across Pakistan may add the health threat to people of the community. The present findings also encouraged us to reassess these samples and further evaluation of various other environmental sources (i.e., air, soil and water) to know the potential pathogenic amoebic species in the environment which will be helpful for health professionals to adopt strategy for future outbreak caused by Naegleria in the country.

Hence, awareness among clinicians would be the key which will help in proper diagnosis of Naegleria infections; ultimately, therapeutic measures could be taken for in time treatment. There is an urgent need to explore other environmental sources across Pakistan for more detailed knowledge about the distribution of Naegleria pathogenic species and their potential threat to human health.

In addition, Naegleria-bacteria interactions also affect bacterial virulence. There is a possible danger that Naegleria may be used as breeding ground for different pathogenic bacteria, which could be a potential threat to human health. The author's future plans are to elucidate the Naegleria-bacteria relationship which would also add threat to human community along with Naegleria.

Acknowledgements. Authors express their thanks to Brig. M. F. Murawat, A. W. K. Naizi, S. K. Naizi, Ghazala Shabnum, Abu Turab Khan, Junaid Khan, Abida Akbar, H. M. Shohaib, Ifrah Shafqat, Bismillah Mubeen, and Robina Khan for their remarkable support in sample collection and transportation.

\section{REFERENCES}

Behets J., Declerck P., Delaedt Y., Verelst L., Ollevier F. (2007) Survey for the presence of specific free-living amoebae in cooling waters from Belgian power plants. Parasitol. Res. 100: 12491256

Edagawa A., Kimura A., Kawabuchi-Kurata T., Kusuhara Y., Karanis P. (2009) Isolation and genotyping of potentially pathogenic Acanthamoeba and Naegleria species from tap-water sources in Osaka, Japan. Parasitol. Res. 105: 1109-1117
Gianinazzi C., Schild M., Wuthrich F., Nouir N. B., Fuchslin HansPeter., Schurch N., Gottstein B., Müller N. (2009) Screening Swiss water bodies for potentially pathogenic free living amoeba. Res. Microbiol. 160: 367-374

Greub G., Raoult D. (2004) Microorganisms resistant to free-living amoebae. Clin. Microbiol. Rev. 17: 413-433

Ithoi I., Ahmad A. F., Nissapatorn V., Lau Y. L., Mahmud R., Mak J. W. (2011) Detection of Naegleria Species in Environmental Samples from Peninsular Malaysia. PLoS ONE 6: e24327

Jamerson M., Remmers K., Cabral G., Marciano-Cabral F. (2009) Survey for the presence of Naegleria fowleri Amebae in lake water used to cool reactors at a nuclear power generating plant. Parasitol. Res. 104: 969-978

Larkin M. A., Blackshields G., Brown N. P., Chenna R., McGettigan P. A., McWilliam H., et al. (2007) ClustalW and ClustalX version 2. Bioinformatics 23: 2947-2948

Marciano-Cabral F., Cabral G. A. (2007) The immune response to Naegleria fowleri amebae and pathogenesis of infection. FEMS Immunol. Med. Microbiol. 51: 243-259

Martinez A. J., Visvesvara G. S. (1997) Free-living, amphizoic and opportunistic amebas. Brain Pathol. 7: 583-598

Matin A., Jeong S.-Y. (2011) Interaction of Escherichia coli K1 and E. coli K5 with Acanthamoeba castellanii trophozoites and cysts. Korean J. Parasitol. 49: 349-356

Michel R., Muller K. D., Hauroder B., Zoller L. (2000) A coccoid bacterial parasite of Naegleria sp. (Schizopyrenida: Vahlkampfiidae) inhibits cyst formation of its host but not transformation to the flagellate stage. Acta Protozool. 39: 199-207

Rowbotham T. J. (1986) Current views on the relationships between amoebae, legionellae and man. Isr. J. Med. Sci. 22: 678-689

Saleem T., Rabbani M., Jamil B. (2009) Primary amoebic meningoencephalitis: two new cases from Pakistan. Trop. Doct. 39: 242-243

Shariq A., Afridi F. I., Farooqi B. J., Ahmed S., Hussain A. (2014) Fatal primary meningoencephalitis caused by Naegleria fowleri. J. Coll. Phy. Surg. Pak. 24: 523-525

Schuster F. L., Visvesvara G. S. (2004) Opportunistic amoebae: Challenges in prophylaxis and treatment. Drug Resist Updat. 7: 41-51

Shakoor S., Beg M. A., Mahmood S. F., Bandea R., Sriram R., Noman F., Ali F., Visvesvara G. S., Zafar A. (2011) Primary Amebic Meningoencephalitis Caused by Naegleria fowleri, Karachi, Pakistan. Emer. Infec. Dis. 7: 258-261

Sheehan K. B., Ferris M. J., Henson J. M. (2003) Detection of Naegleria sp. in a thermal, acidic stream in Yellow stone National Park. J. Eukaryot. Microbiol. 50: 263-265

Tamura K., Peterson D., Peterson N., Stecher G., Nei M., Kumar S. (2011) MEGA5: Molecular Evolutionary Genetics Analysis using Maximum Likelihood, Evolutionary Distance, and Maximum Parsimony Methods. Mol. Biol. Evol. 28: 2731-2739

Tanveer T., Hameed A., Gul A., Matin A. (2015) Quick survey for detection, identification and characterization of Acanthamoeba genotypes from some selected soil and water samples in Pakistan. Ann Agric Environ Med. 22: 232-235

Tanveer T., Hameed A., Muazzam A. G., Jung S.-Y., Gul A., Matin A. (2013) Isolation and molecular characterization of potentially pathogenic Acanthamoeba genotypes from diverse water resources including household drinking water from Khyber Pakhtunkhwa, Pakistan. Parasitol Res. 112: 2925-2932

Received on $16^{\text {th }}$ October, 2017; revised on $28^{\text {th }}$ November, 2017; accepted on $12^{\text {th }}$ December, 2017 